\title{
CAMINHOS E DILEMAS DA EDUCAÇÃO AMBIENTAL NO CONTEXTO ESCOLAR
}

\author{
Maria Inêz Oliveira Araujo ${ }^{1}$ \\ Mônica Andrade Modesto ${ }^{2}$ \\ Tatiana Ferreira Santos ${ }^{3}$
}

\begin{abstract}
Resumo
O presente artigo tem como finalidade apresentar as questões elencadas no GPD Educação Ambiental no Contexto Escolar, refletir sobre o que foi identificado e apresentar os encaminhamentos que possam indicar contribuições para os pensares e fazeres que constituíram os caminhos e dilemas, nas apresentações e debates presenciados durante os dois dias de discussão, durante o VIII Encontro de Pesquisa em Educação Ambiental. As questões apresentadas no grupo abordaram temas como: aspectos teórico-metodológicos, currículo, políticas públicas, formação de professores, educação ambiental crítica e programas implementados no contexto escolar. Sobre as pesquisas realizadas, a de intervenção foi a mais utilizada. Ao final, foram explanados encaminhamentos coletivos que têm como elemento fundante a esperança pela abertura de mais caminhos no que diz respeito à educação ambiental.
\end{abstract}

Palavras-chave: Educação Ambiental. Contexto escolar. Questões de pesquisa.

\section{PATHS AND DILEMMAS OF ENVIRONMENTAL EDUCATION IN SCHOOL CONTEXTS}

\begin{abstract}
This article aims to present the listed issues in GPD Environmental Education in the school contexts, reflect on what has been identified, and provide referrals that may contribute to the thoughts and doings that were the paths and dilemmas found in presentations and debates carried out during the two days of discussion at the VIII Research Meeting in Environmental Education. The questions presented as group topics were: theoretical and methodological aspects, curriculum, policies, teacher education, critical environmental education and programs implemented in the school contexts. Among the research conducted, the intervention type was the most used. At the end, collective referrals founded on the hope of the opening of more routes to environmental education were explained.
\end{abstract}

Keywords: Environmental Education. School Environment. Research Questions.

\footnotetext{
${ }^{1}$ Professora Associada do Departamento de Educação e do mestrado e doutorado do Programa de Pós-

Graduação em Educação da Universidade Federal de Sergipe PPGED/UFS. inez@ufs.br

2 Mestre em Educação pelo PPGED/UFS, professora efetiva de rede pública do estado de Sergipe. monicamodesto1@gmail.com

${ }^{3}$ Mestre em Educação pelo PPGED/UFS, professora e coordenadora do curso de Serviço Social da Universidade Tiradentes. tatianaferreira1@yahoo.com.br
} 


\title{
CAMINOS Y DILEMAS DE LA EDUCACIÓN AMBIENTAL EN EL CONTEXTO ESCOLAR
}

\author{
Resumen \\ Este artículo tiene como objetivo presentar las cuestiones que figuran en GPD Educación \\ Ambiental en el Contexto Escolar, reflexionar sobre lo que se ha identificado y presentar los \\ pasos que pueden indicar las contribuciones a los pensares y haceres que constituyeron los \\ caminos y dilemas que se perciben en las presentaciones y debates presenciados durante los \\ dos días de debates en el VIII Encuentro de Investigación en Educación Ambiental. Las \\ cuestiones presentadas en el grupo atravesaron temas como aspectos teóricos y \\ metodológicos, planes de estudio, políticas públicas, formación de docentes, educación \\ ambiental crítica y programas implementados en el contexto escolar. Sobre las \\ investigaciónes hechas, la de intervención fue la más utilizada. Por lo tanto, al final se han \\ descritos las acciones colectivas que se considera fundante a la esperanza mediante la apertura \\ de más rutas con respecto a la educación ambiental.
}

Palabras-clave: Educación Ambiental. Contexto Escolar. Cuestiones de Investigación.

\section{Introdução}

Os princípios de ser um processo contínuo, de se realizar em caráter interdisciplinar e de ter a sustentabilidade como finalidade, ao tempo em que se faz urgente, impõem à educação ambiental desafios para a sua implementação na educação formal.

Considerando o ambiente nas suas múltiplas redes de relação, concordamos que a educação ambiental tem como principal objetivo desenvolver um modelo societário que tenha como referência o bem-estar da população, boa qualidade de vida, sem que haja prejuízo social e ambiental para os atuais e futuros habitantes da Terra.

Araujo (2004), apoiada em Morin (2000), argumenta que alguns fenômenos ocorridos no planeta, desencadeados pela ação humana, podem provocar resultados não previsíveis. Esses fenômenos, muitas vezes, são tratados na escola sem que haja reflexão sobre eles em diferentes realidades, sobretudo em realidades específicas, assim como não existe uma reflexão sobre sua influência no contexto social, ambiental e individual, na atualidade. $\mathrm{O}$ mesmo acontece com os conceitos histórica e cientificamente aceitos. Essa forma de tratar os conteúdos em contexto escolar, por vezes não alcança os objetivos da educação ambiental. Sauvé (2005, p. 318-319)), ao falar sobre o meio ambiente, afirma que:

É um lugar de cooperação e de parceria para realizar mudanças desejadas no seio da coletividade. [...] O meio ambiente é um objeto compartilhado, essencialmente complexo [...]. É preciso que se aprenda a discutir, a argumentar, a convencer, em suma, a comunicar-se eficazmente por meio de um diálogo entre saberes de diversos tipos - científicos, de experiências, tradicionais etc. A educação ambiental introduz aqui a ideia de práxis: a ação está associada a um processo constante de reflexão crítica.

Esse olhar de Sauvé sobre meio ambiente coaduna-se com as preocupações apontadas pela UNESCO, quando institui o período de 2005 a 2014 como a Década Internacional da Educação para o Desenvolvimento Sustentável. Não por acaso, o VIII Encontro de Pesquisa em Educação Ambiental - EPEA elegeu a avaliação dessa década como tema central para a sua oitava edição. Nesse sentido, o Grupo de Discussão de Pesquisa - GDP Educação ambiental no contexto escolar tomou, como centro das suas reflexões, o tema Avaliação da Década Internacional da Educação para o Desenvolvimento Sustentável e Perspectivas Futuras. Segundo o texto de referência para a condução de nossas reflexões, no referido 
grupo, a "[...] educação para o desenvolvimento sustentável permite a todo ser humano adquirir conhecimento, habilidades, atitudes e valores necessários para formar um futuro sustentável". É nessa perspectiva que o presente ensaio tem como objetivo apresentar as reflexões sobre os avanços, os enfrentamentos e desafios no campo da educação ambiental realizados durante o GDP mencionado, realizado em julho de 2015, na cidade do Rio de Janeiro.

A metodologia utilizada na condução das discussões no GDP teve como orientação os objetivos propostos pelo VIII EPEA, os quais apresentamos a seguir:

- Refletir sobre as relações entre a temática ambiental e o campo da pesquisa em educação ambiental.

- Discutir as implicações da temática ambiental, compreendida como problema na sociedade contemporânea, para os processos de produção de conhecimento no campo da educação ambiental.

- Analisar experiências de pesquisas em educação ambiental e as relações que têm se estabelecido entre questões suscitadas pela temática ambiental para a sociedade contemporânea e os processos de produção de conhecimento para a educação e a educação ambiental.

- Avaliar a década da educação para o desenvolvimento sustentável e os novos rumos da pesquisa em educação ambiental (VIII EPEA, 2015).

Assim, organizamos a discussão em dois momentos. O primeiro, dedicado às apresentações dos pesquisadores e dos seus respectivos projetos, ocasião que propiciou conhecer a origem dos pesquisadores, o lugar de onde falavam, as ações desenvolvidas, os enfrentamentos, os avanços e contribuições.

O segundo, dedicado ao aprofundamento das questões. Nessa etapa, retomamos os conceitos veiculados na fase anterior e buscamos refletir sobre eles. Dessa forma, buscamos aprofundar as questões teóricas que foram evidenciadas na prática da educação ambiental dos pesquisadores e pensar em contribuições para o avanço das pesquisas em EA.

Nessa edição foram aprovados 39 (trinta e nove) trabalhos no GDP Educação Ambiental e Contexto Escolar. Nem todos os autores que tiveram seus trabalhos aprovados compareceram à reunião do GDP, mas os que se fizeram presentes compuseram uma quantidade representativa, visto que o grupo estava formado por pesquisadores, professores da educação básica e membros de instituições públicas e privadas que atuam, direta ou indiretamente, na educação formal e não formal de diferentes estados: Acre, São Paulo, Mato Grosso do Sul, Paraná, Sergipe, Bahia/Colômbia (pesquisador colombiano em exercício em Salvador), Espírito Santo e Rio de Janeiro.

\section{Objetos de estudo}

A perspectiva de inserir as questões ambientais no processo educativo requer uma prática docente que promova o desenvolvimento de habilidades e atitudes, a qual permita que o aluno aja, ativamente, na sociedade, e possibilite ao professor o desenvolvimento constante de novas atitudes necessárias ao bom desempenho de sua profissão, alinhadas e adaptadas às novas exigências sociais, na perspectiva de alcançar os objetivos propostos por essa nova forma de conceber a educação. (ARAUJO, 2004).

Respeitando esse viés, os trabalhos apresentados foram agrupados nos seguintes objetos de pesquisas:

1- Concepções e representações de meio ambiente e educação ambiental de alunos e professores.

2 - Agronegócio na escola pública.

3 - Inserção curricular da EA no Ensino Superior e Básico.

4 - Tendências na EA. 
5 - Práticas didáticas e pedagógicas em ambiente escolar e não escolar.

6 - Formação de professores na perspectiva da educação ambiental na relação universidade/escola.

Considerando que a forma como vemos ou representamos o meio ambiente pode auxiliar na organização do trabalho pedagógico, verificamos que, a exemplo de alguns trabalhos publicados sobre concepções, representações e percepções de meio ambiente e de educação ambiental, os objetivos e resultados das pesquisas não ultrapassaram a classificação quanto às macrotendências da educação ambiental ou da natureza do ambiente. Apesar das pesquisas já mostrarem certo avanço nas concepções de ambiente, no que diz respeito a conceberem o meio não apenas como natural, mas já inserindo o ser humano e, portanto, o aspecto social, precisamos avançar na pesquisa.

Se faz mister avançar no sentido do que fazer com essas concepções, pois, ainda está presente a visão dicotômica, apesar de que, quando consultados, professores e alunos apresentam o conceito complexo-integrado do ambiente, no entanto, ainda não se evidencia nas práticas desenvolvidas na escola, avanços significativos na formação ambiental dos estudantes, aqui podemos inferir que se trata do que Mauro Guimarães denomina de Armadilha Paradigmática. O que se constitui um grande dilema, visto que os pesquisadores ficam no discurso não intencional - aquele que é dito sem que conheça, a fundo, o assunto abordado. Concordamos com Foucault (1996) quando afirma que o discurso não é, simplesmente, aquilo que manifesta o desejo; é, também, aquilo que é o objeto de desejo; não é o que se traduz nas lutas ou nos sistemas de dominação, mas aquilo de que queremos nos apoderar.

Os discursos sobre educação ambiental podem ser compreendidos como práticas geradoras de significados que se apoiam na relação valores-conduta para estabelecer regras de convivência e o desenvolvimento ético socioambiental. Esse discurso teria o sentido que Foucault atribuiu ao discurso verdadeiro, aquele que "[...] profetizando o futuro, não somente anunciava o que ia se passar, mas contribuía para sua realização, suscitava a adesão dos homens e se tramava assim com o destino" (FOUCAULT, 1996, p.15).

A educação ambiental, pensada e descrita pela literatura mais recente, sinaliza para uma educação que potencialize o indivíduo para uma visão crítica sobre a realidade socioambiental, cultural e política. No entanto, o discurso posto na literatura não aparece na prática cotidiana das escolas. Além de estar distante da realidade das escolas, quando se faz presente não tem contribuído para a formação da identidade de uma educação própria à realidade brasileira. Isso se observa pelas inúmeras formas de entendimento e práticas educacionais desenvolvidas no país. Concordamos com Ruscheinsky e Bortolozzi (2014, p.47), quando afirmam que "são raras as práticas que se destacam como transformadoras".

Mesmo acreditando no discurso, apoiados em Foucault, percebemos nesse dilema o que Guimarães (2011) denomina de armadilha paradigmática. Nela, observam-se práticas em que há uma intenção de promover a relação entre meio ambiente e ensino com vistas a uma conscientização e a uma possível mudança de comportamento, mas o discurso fica limitado a uma visão ingênua e ao paradigma simplista da sociedade moderna, que reduz a realidade e tende a reproduzir discursos e práticas consolidadas, o que causa uma "compreensão limitada da problemática ambiental" (GUIMARÃES, 2011, p. 24).

De acordo com esse autor, a armadilha paradigmática pode resultar, também, em práticas que visam a corrigir atitudes ecologicamente incorretas, que remetem ao princípio do $1+1=2$, na esperança de promover uma transformação da sociedade. Portanto,

Para o processo formativo, em uma vertente crítica, romper com essa armadilha é oportunizar uma reflexão crítica em práticas diferenciadas de intervenção na realidade, que possam, pela intencionalidade da construção de outra realidade, manifestar uma práxis pedagógica (GUIMARAES; QUEIROZ; PLÁCIDO, p.115, 2014). 
Daí a necessidade de conhecer as concepções, mas não parar nelas. Conhecer as concepções dos alunos e professores é o primeiro passo para a abordagem metodológica. Nesse sentido, Ruscheinsky e Bortolozzi (2014, p.47) argumentam sobre a relevância de "se enfatizar a questão primeiramente a partir de uma visão de mundo ou de um horizonte socioambiental para elaborar uma contribuição metodológica".

As discussões também fluíram para o campo da formação do professor e do profissional de diferentes áreas, a partir do entendimento de que todos os profissionais devem incorporar os princípios da educação ambiental na formação e, assim, exercerem, profissionalmente, sua função social com eficiência.

Nesse cenário, surgem algumas relações que desafiam o professor a ocupar o espaço de mediador da aprendizagem dos seus alunos. A visão tradicional do professor como dono do saber dá lugar à figura do professor como facilitador e parceiro da aprendizagem. A relação vertical entre aluno-professor abre espaço para uma relação de compartilhamento de opiniões e estratégias. Essas novas relações foram mais enfaticamente difundidas, nas últimas décadas, por expressões como: fazer-aprendendo, aprender-fazendo, aprender a aprender, todas fundadas no desejo de unir a teoria à prática, de transformar o processo de aprendizagem como indissociável do conteúdo a ser aprendido.

Essa perspectiva remete ao segundo tópico: as práticas pedagógicas em ambientes escolares e não escolares. Nesse sentido, observaram-se ações relacionadas à pesquisa, à extensão e à intervenção, sendo que os últimos tipos sobressaíram em relação ao primeiro. Pesquisa e extensão são de grande importância no processo de formação docente, todavia, não se pode considerar que ações que resultam em intervenção são mais fecundas do que ações que resultam em investigação, afinal, teoria e prática são complementares e não dicotômicas.

Desse modo, foram apresentados, no grupo, diferentes procedimentos de construção de conhecimento, em sua maioria baseados em trabalho de campo e de intervenção. No entanto, foi possível verificar que muitos dos trabalhos estavam vinculados ao fazer como prática extensionista, sem a intencionalidade de pesquisa, mas de contribuir na formação do indivíduo. Essa prática pedagógica oportuniza, aos sujeitos nela envolvidos, reflexões sobre os conceitos culturalmente produzidos no vivido das sociedades, mas não pode ocorrer de maneira dissociada de reflexões dos conhecimentos cientificamente produzidos ao longo do tempo. Tal afirmação corrobora o pensamento de Santos $(2004$, p. 31), quando defende que é preciso que a sociedade entre na universidade e que a universidade entre na sociedade.

Ações de pesquisa e de extensão, por sua vez, são uma forma de inserir a educação ambiental no currículo dos cursos de Ensino Superior, visto que, além das disciplinas, ele é também composto por atividades complementares.

Concernente à educação ambiental, a sua inserção em cursos de graduação passou a ser assegurada, legalmente, com a promulgação da Constituição Federal Brasileira, em 1988, que, no Inciso VI, Art. 225, Capítulo VI, destaca a necessidade de "promover a educação ambiental em todos os níveis de ensino e a conscientização pública para a preservação do meio ambiente" (BRASIL, 2013, p. 45). Todavia, foi só a partir da Política Nacional de Educação Ambiental, em seu Art. $2^{\circ}$, que a educação ambiental passou a ser legitimada como "um componente essencial e permanente da educação nacional, devendo estar presente, de forma articulada em todos os níveis e modalidades do processo educativo, em caráter formal e não formal" (BRASIL, 1999, p. 1).

A partir daí, muitas discussões emergiram em torno da disciplinarização da educação ambiental nos currículos. A legislação educacional e os documentos norteadores da educação ambiental orientam que a sua presença nos currículos não deve ser restrita a uma disciplina ou a um conteúdo, antes, deve perpassar todos os campos do conhecimento. 
No que diz respeito à educação básica, com a reformulação da LDB/1996, foi acrescentado um parágrafo ao Art. 26, inciso VI, que determina que "os currículos do ensino fundamental e médio devem incluir os princípios da proteção e defesa civil e a educação ambiental de forma integrada aos conteúdos obrigatórios" (BRASIL, 2013, p. 20). Essa integração remete à questão da transversalidade do conteúdo e à interdisciplinaridade da prática pedagógica, em um movimento de transição do paradigma tradicional do ensino e da produção do conhecimento para o paradigma crítico, que reconhece a heterogeneidade do pensamento dos indivíduos.

Logo, a educação ambiental requer uma perspectiva metodológica sob o enfoque interdisciplinar na qual, à medida que o aluno se apropria do conteúdo, exercita a alteridade, o respeito, a solidariedade, a argumentação e, com isso, desenvolve valores e atitudes éticas em favor da conservação do meio natural e para a defesa dos direitos humanos para todos, irrestritamente.

Assim, o processo de aquisição de conhecimento é imperativo na formação de valores e atitudes éticas profissionais dos futuros professores. A partir desse conhecimento, é possível vislumbrar a transcendência do estágio de sensibilização dos problemas ambientais, comuns nas práticas tradicionais, para a tomada de consciência, capaz de gerar ação (ARAUJO; BIZZO, 2015).

Concernente a esse cenário educacional, é possível observar, em documentos e práticas pedagógicas, duas macrotendências da educação ambiental: conservadora e emancipatória. A educação ambiental conservadora é uma forma de compreensão de mundo moldada pela racionalidade hegemônica, que fragmenta a construção do conhecimento, mantém o status quo da sociedade e gera práticas que reforçam essa forma de pensar. Já a educação ambiental emancipatória requer uma prática crítica, que se distancia do sentimento romantizado e utilitarista do ambiente e de nós mesmos, e se desvela em práxis.

É no desvelar da práxis pedagógica que a realidade concreta vincula-se aos processos teóricos que subsidiam a reflexão crítica, permitindo, talvez, uma ação sobre essa mesma realidade e, desejavelmente, a reflexão sobre a ação, favorecendo que tanto o professor quanto o aluno vivenciem o processo de ensino e aprendizagem, considerando suas visões de mundo, tornando-as práticas pedagógicas transformadoras, possibilitando que a transformação social ocorra através da educação (MÉSZÁROS, 2008).

É nessa direção que a defesa pela inserção curricular da EA no ensino superior e básico caminha. Ambas amparadas por documentos oficiais que defendem o trato da questão ambiental na formação em diferentes níveis. Mesmo com a existência da PNEA e das Diretrizes Curriculares Nacionais para a Educação Ambiental, seus processos ainda são escassos em escolas básicas e superiores. Por ainda se constituir distante da realidade em que os processos educativos ocorrem pelos antagonismos e contradições da aplicação das políticas educacionais e os desafios e dificuldades enfrentadas diariamente por milhares de educadores no Brasil, ainda serão necessários vários anos para que os documentos oficiais sejam cumpridos concretamente, contemplando, de forma integrada, a formação ambiental necessária.

Nesse sentido, os trabalhos apresentados sobre a inserção curricular da EA no Ensino Superior e Básico elucidaram perspectivas acerca dos pontos positivos e negativos da disciplinarização da EA, considerando diferentes realidades, a exemplo das experiências das escolas de Ensino Básico em que foi instituída a EA como disciplina e apresentaram experiências de sucesso, ou os casos dos processos interdisciplinares envolvendo a EA nas escolas desse nível de ensino. O debate foi ampliado para a ambientalização do currículo no Ensino Superior, em que foram discutidas as lacunas existentes nos documentos oficiais, que dificultam, ainda mais, a efetivação da EA nos currículos. 


\section{Sobre a educação ambiental no contexto escolar}

Como metodologia, foram apresentados, no grupo, diferentes procedimentos de construção de conhecimento, em sua maioria, baseados no trabalho de campo e de intervenção. No entanto, foi possível verificar que muitos dos trabalhos estavam vinculados ao fazer como prática extensionista, sem a intencionalidade de pesquisa, mas de contribuir na formação do indivíduo.

Partindo do estudo dos autores mais citados, podemos inferir que a concepção mais presente nas propostas está alinhada com a macrotendência de educação ambiental crítica. Os autores mais citados foram Carlos Frederico Loureiro, Isabel Cristina Moura Carvalho, Luiz Marcelo de Carvalho, Mauro Guimarães, Philippe Layrargues, Marcos Reigota, Tozzoni-Reis e Michèle Sato.

\section{Considerações}

Diante do exposto, podemos concluir que ainda não foi encontrado o caminho viável e factível para se inserir os princípios da educação ambiental no cotidiano escolar, visto que o sistema escolar não permite que as atividades didáticas possam ir além de práticas isoladas e pontuais, as quais não levam o aluno à criticidade. Assim, implementar a educação ambiental no contexto da escola ainda é um grande desafio.

Para que a escola alcance seus objetivos, no sentido de inserir as questões ambientais no processo educativo, faz-se mister articular a escola com espaços não escolares. Os alunos devem vivenciar experiências fora dos muros escolares e discuti-las em sala de aula. Com essa articulação, vislumbra-se a contextualização dos conteúdos e, consequentemente, o desenvolvimento do senso crítico e de atitudes participativas.

Uma das limitações para o desenvolvimento da educação ambiental no contexto escolar está na forma como o projeto pedagógico é elaborado. Geralmente, são elaborados por um pequeno grupo para toda comunidade escolar implementar. De acordo com as reflexões, ficou evidenciada a necessidade de mais estudos sobre a elaboração e implementação do PPP sugerindo a participação e envolvimento de todos profissionais do estabelecimento escolar, na perspectiva de que, ao planejarem as ações e metas, o façam 'com', 'na' e 'para' escola.

Especificamente com relação às pesquisas, foi apontada, como encaminhamento para o avanço da educação ambiental no contexto escolar, a necessidade de criar mais espaços de compartilhamento das pesquisas do chão da escola. Atualmente, existem espaços de divulgação de pesquisas científicas produzidas na academia, mas não há espaços para os professores compartilharem suas experiências de pesquisa.

Por fim, a reflexão enfatizou a necessidade de investigar as políticas de formação para escolas sustentáveis.

\section{Referências}

ARAUJO, M. I. O. A dimensão ambiental no currículo do curso de formação de professores de Biologia. 2004. 2 volumes. Tese (Doutorado em Educação) - Programa de Pós-Graduação da Faculdade de Educação da Universidade de São Paulo, São Paulo, 2004.

ARAUJO, M. I. O.; BIZZO, N. Processo investigativo sobre práticas pedagógicas para inserção da dimensão ambiental na formação de professores de Biologia. Tempos e Espaços em Educação, São Cristóvão, v. 8, n.16, p.125-138, mai-jun. 2015. Disponível em:

<www.seer.ufs.br/index.php/revtee/article/view/3978/3325>. Acesso em: 15 mai. 2016. 
BRASIL. Constituição da República Federativa do Brasil. Texto consolidado até a Emenda Constitucional nº 64, de 04 de fevereiro de 2010. Brasília: Senado Federal, 2013.

BRASIL. Lei 9.394, de 20 de dezembro de 1996. Dispõe sobre as Diretrizes e Bases da Educação Nacional. Brasília: Casa Civil, 1996. Disponível em: <http://www.planalto.gov.br/ccivil_03/Leis/L9394.htm>. Acesso em: 12 dez. 2014.

BRASIL. Lei 9.795, de abril de 1999. Dispõe sobre a educação ambiental, institui a Política Nacional de Educação Ambiental e dá outras providências. Brasília: Casa Civil, 1999. Disponível em: <http://www.planalto.gov.br/ccivil_03/leis/19795.htm>. Acesso em: 6 fev. 2015.

FOUCAULT, M. A ordem do discurso. Tradução Laura F. de Almeida Sampaio. São Paulo: Loyola, 1996.

GUIMARÃES, M. Armadilha paradigmática na educação ambiental. In: LOUREIRO, C.F.B.; LAYRARGUES, P. P.; CASTRO, R. S. (Orgs.). Pensamento complexo, dialética e educação ambiental. 2 ed. São Paulo: Cortez, 2011. p.11-29.

GUIMARÃES, M.; QUEIROZ, E. D. de; PLÁCIDO, P. De O. Reflexões sobre a pesquisa na formação de professores/educadores ambientais. In: Revista Pesquisa em Educação Ambiental, São Carlos, v.9, n.1, p. 110-119, jan/jun. 2014. Disponível em:

<http://www.periodicos.rc.biblioteca.unesp.br/index.php/pesquisa/issue/view/968>.

Acesso em: 14 mai. 2016.

MÉSZÁROS, I. A educação para além do capital. 2ed. São Paulo: Boitempo, 2008.

RUSCHEINSKY, A.; BORTOLOZZI, A. Educação Ambiental e alguns aportes metodológicos da ecopedagogia para inovação de políticas públicas urbanas. In: PEDRINI, A. de G.; SAITO, C. H. (Orgs.). Paradigmas metodológicos em educação ambiental. Rio de Janeiro: Vozes, 2014. p.47-59

SANTOS, B. de S. A universidade no século XXI. São Paulo: Cortez, 2004.

SAUVÉ, L. Educação Ambiental: possibilidades e limitações. In: Educação e Pesquisa,São Paulo, v.31, n. 2 p. 317-322, mai/ago. 2005. 